\title{
Molecular Characteristics and Exotoxins of Methicillin-Resistant Staphylococcus aureus
}

\author{
Jinyoung Bae ${ }^{1,2, *}$, Hyunwoo Jin ${ }^{1,2, * * *}$, Jungho Kim ${ }^{1,2, * *}$, Min Park ${ }^{3, * * *}$, \\ Jiyoung Lee $\mathrm{Ce}^{1, \dagger ; * *}$ and Sunghyun Kim ${ }^{1,2, \dagger, * * *}$ \\ ${ }^{I}$ Department of Clinical Laboratory Science, College of Health Sciences, \\ Catholic University of Pusan, Busan 46252, Korea \\ ${ }^{2}$ Clinical Trial Specialist Program for In Vitro Diagnostics, Brain Busan 21 Plus Program, \\ Graduate School, Catholic University of Pusan, Busan 46252, Korea \\ ${ }^{3}$ Department of Biomedical Laboratory Science, Masan University, Changwon-si 51217, Korea
}

\begin{abstract}
Methicillin-resistant Staphylococcus aureus (MRSA) is a bacterial pathogen capable of causing human diseases, such as soft tissue infection, bacteremia, endocarditis, toxic shock syndrome, pneumonia, and sepsis. Although the incidence rate of diseases caused by MRSA has declined in recent years, these diseases still pose a clinical threat due to their consistently high morbidity and mortality rates. However, the role of virulence factors in staphylococcal infections remains incompletely understood. Methicillin resistance, which confers resistance to all $\beta$-lactam antibiotics in cellular islets, is mediated by the mecA gene in the staphylococcal cassette chromosome mec (SCCmec). Differences in SCCmec types and differences in their sizes and structures serve epidemiological purposes and are used to differentiate between hospital-associated (HA)-MRSA and community-associated (CA)-MRSA. Some virulence factors of S. aureus are also providing a distinction between HA-MRSA and CA-MRSA. These factors vary depending on the presence of toxins, adhesion, immune evasion, and other virulence determinants. In this review, we summarized an overview of MRSA such as resistance mechanisms, SCCmec types, HA- and CA-MRSA, and virulence factors that enhance pathogenicity or MRSA epidemiology, transmission, and genetic diversity.
\end{abstract}

Key Words: Methicillin-resistant Staphylococcus aureus (MRSA), Staphylococcal cassette chromosome mec, Hospitalassociated-MRSA, Community-associated MRSA, Exotoxins

\section{INTRODUCTION}

Staphylococcus aureus is a major bacterial pathogen that causes a range of infectious diseases in humans, including skin infections, bacteremia, endocarditis, toxic shock syndrome (TSS), pneumonia, and sepsis (Tong et al., 2015). Although $S$. aureus is usually a commensal bacterium, it can cause infection in immunocompromised patients or during surgery with invasive medical devices (Anderson et al.,

Received: October 21, 2021 / Revised: December 3, 2021 / Accepted: December 3, 2021

*Graduate student, ${ }^{* *}$ Post-Doctor, ${ }^{* * *}$ Professor.

${ }^{\dagger}$ Corresponding author: Jiyoung Lee. Department of Clinical Laboratory Science, College of Health Sciences, Catholic University of Pusan, Busan 46252, Korea.

Tel: +82-51-510-0569, Fax:+82-51-510-0568, e-mail: aez1827@gmail.com

${ }^{\dagger}$ Corresponding author: Sunghyun Kim. Department of Clinical Laboratory Science, College of Health Sciences, Catholic University of Pusan, Busan 46252 , Korea

Tel: +82-51-510-0560, Fax:+82-51-510-0568, e-mail: shkim0423@cup.ac.kr

(C)The Korean Society for Biomedical Laboratory Sciences. All rights reserved.

(9)This is an Open Access article distributed under the terms of the Creative Commons Attribution Non-Commercial License (http://creativecommons.org/licenses/by-nc/3.0/) which permits unrestricted non-commercial use, distribution, and reproduction in any medium, provided the original work is properly cited. 
2012; Moran et al., 2012; Nimmo, 2012; Tong et al., 2012).

There are many kinds of antibiotics that target key bacterial processes, such as cell wall synthesis, translation, transcription, and DNA synthesis, and that can be used to treat staphylococcal infections (Samanta and Elasri, 2014; Assis et al., 2017; G et al., 2019). Methicillin-resistant $S$. aureus (MRSA) attracted global attention in the 1960s (Benner and Kayser, 1968; Chambers and Deleo, 2009; Melo et al., 2017; Fri et al., 2020), and its antibiotic resistance occurs via several mechanisms. Currently, MRSA has spread globally, and its prevalence has increased both in hospitalassociated MRSA (HA-MRSA) and community-associated MRSA (CA-MRSA) (Saiman et al., 2003; Bratu et al., 2005; Gregory et al., 2009; Sassi et al., 2017).

Infectious diseases caused by MRSA include superficial skin and soft tissue infections, endocarditis, bacteremia, necrotizing pneumonia, fasciitis, and osteomyelitis, all of which are life-threatening conditions. The emergence of MRSA strains has resulted in severe mortality and morbidity because of the spread of these strains in hospitals and communities (Bratu et al., 2005). MRSA tends to occur during population infections, often characterized by a series of predominant strains. MRSA infection without a single predominant strain also occurs worldwide, and it is more difficult to treat. In order to address the problem caused by MRSA, guidelines have been published in several countries. There are recommendations for the identification of MRSA, as well as protocols and procedures for the diagnosis of MRSA. These guidelines include the Clinical and Laboratory Standards Institute (CLSI; formerly the National Clinical Laboratory Standards, NCCLS) in the USA, the European Antimicrobial Resistance Surveillance System (EARSS) in Europe, and the Sociedad Española de Infectologia y Microbiologia Clinica (SEIMC) in Spain.

MRSA has a copy of the mec gene, which is located in the staphylococcal cassette chromosome mec (SCCmec), which encodes the penicillin-binding proteins (PBPs) with reduced affinity for $\beta$-lactam antibiotics. These PBPs include $m e c \mathrm{~A}, m e c \mathrm{~B}, m e c \mathrm{C}$, and $m e c \mathrm{D}$ (Harrison et al., 2013; Gomez-Sanz et al., 2015; Schwendener and Perreten, 2018). The resistance of MRSA infections to all types of $\beta$-lactam antibiotics, such as penicillin and methicillin, makes its treatment challenging. Other antibiotics, such as mupirocin, bind to the enzyme leucine-specific tRNA aminoacyl synthetase and inhibit protein synthesis. However, long-term and widespread use of mupirocin for decolonization has been associated with mutations in the MupA gene and chromosomal point mutations, conferring mupirocin resistance (Hayden et al., 2016; Dadashi et al., 2020). The macrolide antibiotic fusidic acid is commonly used to treat skin infections caused by $S$. aureus (Liu et al., 2017; Chen et al., 2020; Liu et al., 2020). In S. aureus, the main resistance mechanism to various types of antibiotics is the pumpmediated efflux mechanism (da Cruz et al., 2020). The multidrug efflux pumps found in $S$. aureus are grouped into five families of membrane proteins: the ATP-binding cassette, small multidrug resistance family, major stimulator superfamily (MFS), resistant nodular division superfamily, and multidrug and toxin extrusion family (Jang, 2016). Furthermore, MRSA strains have additional virulence factors, such as toxins and adhesion proteins (Alvaro-Afonso et al., 2018; Smart et al., 2019).

Recently, studies have focused on various virulence factors that play important roles in the pathogenesis of MRSA, which are encoded by multiple genes (Boulton et al., 2005; Shettigar and Murali, 2020). Exotoxins, which are virulence factors of $S$. aureus, secrete different staphylococcal enterotoxins (SEs), such as staphylococcal enterotoxins from types A to U and TSS toxin-1 (TSST-1) (Wang et al., 2008; Krakauer and Stiles, 2013). Exotoxins are superantigens (SAgs) because they combine with the major histocompatibility complex class II molecules in antigenic cells and variable beta region of T-cell receptors to activate $\mathrm{T}$ cells more strongly than during normal $\mathrm{Ag}$ reactions and cause strong inflammatory reactions (Proft and Fraser, 2003; Loncarevic et al., 2005). SE, an exotoxin of S. aureus, is prevalent worldwide, causes gastrointestinal syndrome in humans, which presents with food poisoning, vomiting, and diarrhea (Lovseth et al., 2004; Oliveira et al., 2018).

Other virulence factors include Panton-Valentine leucocidin (PVL), encoded by the $l u k S / F-P V$ and $l u k E / D$ genes, exfoliative toxins (ETs) (Ladhani, 2001; Rasheed and Hussein, 2020), arginine catabolic mobile element (ACME, arcA), $\beta$-hemolysin (hlb), TSST-1, accessory gene regulator 


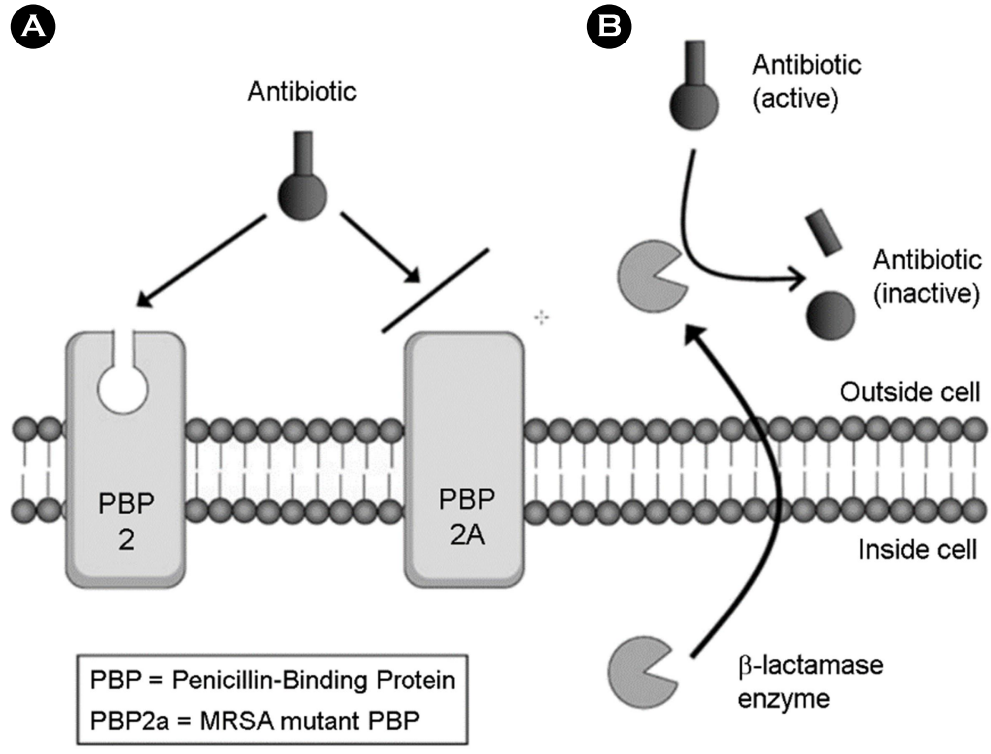

Fig. 1. Diagram of the two principal antibiotic resistance mechanisms observed in MRSA bacteria. (A) Expression of an alternate form of penicillin-binding protein (PBP2), PBP2a, with reduced binding affinity for antibiotics. (B) Production and release of the $\beta$-lactamase enzyme, which cleaves antibiotic molecules and renders them inactive. The illustration is adapted from Murphy et al. (Murphy et al., 2011). (agr), and $\alpha$-hemolysin (hla) (Yarwood et al., 2004; Scherr et al., 2015). This review aims to provide an understanding of the mechanism of exotoxins and the molecular characteristics of $S$. aureus, focusing on MRSA strains and summarizing the current epidemic and virulence factors of MRSA.

Recent epidemiological studies of $S$. aureus have focused particularly on the distribution of MRSA in healthcare settings and communities. However, in the past century, methicillin-susceptible $S$. aureus (MSSA) was also a major cause of outbreaks and global spread in healthcare settings. Moreover, it remains as one of the leading pathogens of hospital-acquired infections (Monaco et al., 2017).

\section{Mechanisms of methicillin resistance}

MRSA contains mecA gene that encodes the peptidoglycan transpeptidase, PBP2a, which reduces the affinity for $\beta$-lactam antibiotics (Fishovitz et al., 2014). $\beta$-lactam antimicrobial agents target and inhibit bacterial cell wall biosynthesis, particularly the synthesis of the peptidoglycan layer (Sarkar et al., 2017). Peptidoglycan is a major structural component of the cell wall and is made of glycan strands, which are composed of repeating patterns of Nacetylglucosamine and $\mathrm{N}$-acetylmuramic acids that form peptide crosslinks between the $\mathrm{N}$-acetyl muramic acid moieties of adjacent strands (Peacock and Paterson, 2015). For the past 75 years, $\beta$-lactams have been known to be the most important class of antibiotics used for the treatment of $S$. aureus infections, but some strains of $S$. aureus were found to have strong resistance mechanisms in the form of $\beta$-lactamase even before penicillin was marketed (Fair and Tor, 2014; Vestergaard et al., 2019). In addition to transpeptidase activity, $S$. aureus has several PBPs that regulate peptidoglycan synthesis (Typas et al., 2011) (Fig. 1). The combination of $\beta$-lactam antibiotics and PBP slows the formation of the acyl-enzyme complex, essentially blocking the transpeptidase activity of these enzymes (Fisher and Mobashery, 2020). The mecA gene encodes PBP2a, an enzyme that crosslinks peptidoglycans in bacterial cell walls (Srisuknimit et al., 2017). PBP2a has a low affinity for $\beta$ lactams, making it resistant to antibiotics (Baek et al., 2014). $S$. aureus is resistant to almost all antibiotics as a result of a single genetic element- - SCCmec - and this has led to an increase in the number of severe MRSA strains (Lakhundi and Zhang, 2018).

\section{Staphylococcal cassette chromosome mec types of MRSA}

The methicillin resistance of MRSA is primarily caused by the acquisition of mec $\mathrm{A}$ that is located on a mobile genomic island known as SCCmec (Fig. 2) (Senok et al., 2019). MRSA produces PBP $2 \mathrm{a}$, encoded by the mecA gene, which induces methicillin resistance in staphylococci 


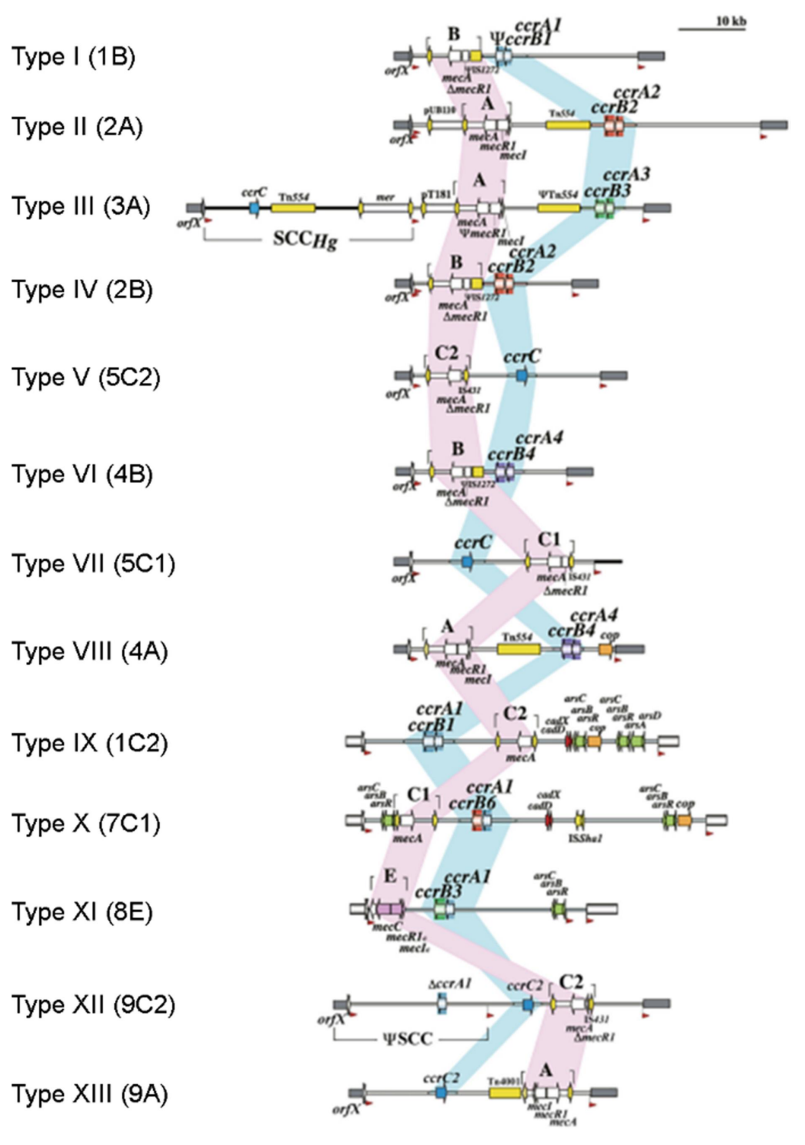

Fig. 2. Genetic features of SCCmec elements I-XIII. Genetic features of SCCmec elements I-XIII. The overall structures of the 13 IWG-SCC-acknowledged SCCmec types are illustrated based on the following nucleotide sequences (SCCmec type), isolate ID (GenBank accession no.): type I, NCTC10442 (AB033763); type II, N315 (D86934); type III, 85/2082 (AB037671); type IV, CA05 (AB063172); type V, WIS [WBG8318] (AB121219); type VI, HDE288 (AF411935); type VII, JCSC6082 (AB373032); type VIII, C10682 (FJ390057); type IX, JCSC6943 (AB505628); type X, JCSC6945 (AB505630); type XI, LGA251 (FR821779.1); type XII, BA01611 (KR187111); and type XIII, 55-99-44 (MG674089). The illustration is adapted from Hiramatsu et al. (Hiramatsu et al., 2013).

(Cikman et al., 2019). SCCmec is a mobile genetic element that ranges from 21 to $67 \mathrm{kbps}$ in size and confers resistance to methicillin in the $S$. aureus species (Hashemizadeh et al., 2019). SCCmec elements are classified into 13 types (SCCmec I to XIII) based on their structural composition and genetic content (Baig et al., 2018; Singh-Moodley et al., 2019). SCCmec types II and III induce resistance to several antibiotics because of the presence of ancillary drug resistance genes in SCCmec, whereas other SCCmec types (I, IV, V, VI, and VII) are known to confer $\beta$-lactam antibiotic resistance (Lim et al., 2019).

\section{Molecular characteristics of HA- and CA-MRSA}

MRSA was first observed in clinical isolates from hospitalized patients in the 1960s. However, it has rapidly spread since the early 1990s (David and Daum, 2010). In many countries, the incidence of HA-MRSA is very high, and the classes of antibiotics that are important for preventing and treating this infection are ineffective (Lindsay, 2013). Numerous CA-MRSA lineages have been found on every continent, and CA-MRSA strains are increasingly involved in nosocomial infections. MRSA is one of the most common causes of hospital- and community-associated infections, most of which have SCCmec types I, II, or III, whereas CA-MRSA strains predominantly have SCCmec type IV or V (Diep and Otto, 2008; Valsesia et al., 2010; Otto, 2013). It is unclear whether CA-MRSA strains are hospital strains that have spread from hospitals or whether these strains have acquired new SCCmec chromosomal DNA (Diederen and Kluytmans, 2006; van Duin and Paterson, 2020).

Monitoring in-hospital outbreaks and identifying worldwide clones are key objectives of the HA-MRSA epidemiologic research. HA-MRSA can spread rapidly in hospitals and replace other $S$. aureus strains (Hart et al., 2014). ST22MRSA-IV (also known as epidemic MRSA (EMRSA)-15) is the most common HA-MRSA clone found in Europe (Aucken et al., 2002). EMRSA-15 was discovered in the early 1990s in southeast England and the Midlands, whereas EMRSA-16 was discovered a year or two later in a hospital epidemic, and both have since spread widely (Aires de Sousa and de Lencastre, 2004). EMRSA-15 and EMRSA16 are genetically diverse, with CC22 (ST22) for EMRSA15 and CC30 (ST36) for EMRSA-16, belonging to different multi-locus sequence type (MLST) clonal complexes (Lindsay, 2010; Silva et al., 2020). EMRSA-15 is the most common clone in the nosocomial and community settings (Johnson et al., 2005).

\section{Virulence factors of $S$. aureus}

Similar to the toxicity of MRSA, the toxicity of $S$. aureus varies depending on the presence of adhesion, toxins, immune evasion, and other virulence determinants (Otto, 2012). 
Clumping factors, fibronectin-binding proteins, adhesions, hemolysins, and various SAgs determine toxicity. Among these, surface proteins can evade innate immune responses, interfere with adaptive immune responses, and function as antigens in vaccines (Foster et al., 2014). Therefore, understanding the cell wall structure of $S$. aureus or the genetic mechanism for expressing proteins is important for its treatment.

\section{4-1. Adhesion genes (clfA, clf $\mathrm{B}, f n b \mathrm{~A}$, and $f n b \mathrm{~B})$}

Clumping factor $\mathrm{A}(\mathrm{ClfA})$, which is involved in a variety of infections, is a representative virulence factor of $S$. aureus (Munoz-Planillo et al., 2009). ClfA is responsible for the accumulation of bacteria in the plasma and can lead to arthritis and endocarditis (Bonar et al., 2015; Herman-Bausier et al., 2018). In addition, clfA promotes invasion of biomaterials coated with plasma proteins and adhesion of bacteria and induces bacterial colonization and biofilm formation (Feuillie et al., 2017). ClfB is only $26 \%$ identical to clfA in the binding domain, but the overall structure is similar ( $\mathrm{D}$ et al., 1998). Unlike $c l f A, c l f B$ binds to fibrinogen by binding to the $\alpha$-chain (Walsh et al., 2008). Interestingly, clfB promotes adhesion to nasal epithelial cells by binding to the keratinized envelope proteins, cytokeratin 10 and loricrin. (Crosby et al., 2016; Foster, 2019). In addition, clfB has recently been shown to promote bacterial adhesion to keratinocytes obtained from patients with atopic dermatitis. Some studies have shown that considerably more clf $\mathrm{B}$ is present in agr mutants than in wild-type cells, indicating that the agr system downregulates $c l f \mathrm{~B}$ gene expression (Xue et al., 2012).

In addition, $S$. aureus expresses microbial surface components that recognize adhesive matrix molecules, including fnbA, fnbB, and fib (Josse et al., 2017). Fibronectin-binding proteins, including FnBPA and FnBPB, are involved in tissue invasion in a variety of pathological conditions, such as ocular keratitis, osteomyelitis, and medical device-borne infections (Soltani et al., 2019). Moreover, fnbA and fnbB are mediators of cell signaling and actin cytoskeleton rearrangements (Hauck and Ohlsen, 2006). The identification of genes related to bacterial colonization has attracted the attention of researchers, and specific primers have been used to determine the frequency of these genes and their mRNA expression levels using polymerase chain reaction (Delgado et al., 2011).

\section{4-2. Hemolysins}

Hla ( $\alpha$-toxin) and hlb are two types of pore-forming toxins (Munoz-Planillo et al., 2009). Hla is a 33-kDa polypeptide secreted by most strains of $S$. aureus, accounting for $95 \%$ of the clinical strains (Oliveira et al., 2018). Although this toxin is not toxic, it confers toxicity by oligomerizing and binding to the heptameric structure of the host cell membrane (Berube and Bubeck Wardenburg, 2013). Once hla binds to the target cell, it oligomerizes to a pre-pore structure and extrudes the $\beta$-barrel through the lipid bilayer to attack the cell membrane, thus forming a hydrophilic transmembrane channel (Voskoboinik et al., 2015; Seilie and Bubeck Wardenburg, 2017). This toxin is known to be widely expressed in human cells, including epithelial cells, endothelial cells, T cells, monocytes, and macrophages (Cikman et al., 2019).

Unlike other cytotoxins, $\beta$-toxin hydrolyzes the plasma membrane lipid sphingomyelin into ceramide and phosphorylcholine without forming pores in the plasma membrane (Lovseth et al., 2004). $\beta$-Toxins also have a DNA biofilmligase activity (Herrera et al., 2017). The $\beta$-toxin of $S$. aureus is neutral sphingomyelinase, whose ability to lyse red blood cells and kill proliferating human lymphocytes is related to its activity (Linehan et al., 2003). This homology led to the hypothesis that $\beta$-toxin could bind and cleave DNA, and the examination of this hypothesis led to the unexpected conclusion that $\beta$-toxin plays a key role (Huseby et al., 2010; Luther et al., 2018).

In addition, mutant strains that do not express the $h l b$ gene for biofilm formation exhibited reduced pathogenicity for endocarditis and are less likely to cause pneumonia and murine ear and skin infections than the strains that express the $h l b$ gene (Typas et al., 2011; Zheng et al., 2019). $\gamma$ hemolysin (hlg) is produced in virtually all strains of $S$. aureus, and $h l g$ can lyse a variety of mammalian erythrocytes (Yoong and Torres, 2013). The $h l g$ gene is transcribed at a single locus on a 4.5 -kb ScaI chromosome fragment (Lovseth et al., 2004). Hemolytic and leukemic toxicity was found in 
extracts from clones containing this fragment (Diep and Otto, 2008). The hlg and PVL in S. aureus make two types of binary toxins called $\mathrm{S}$ and $\mathrm{F}$ components (for proteins that elute slowly or rapidly in ion exchange columns). The Sclass subunit is primarily responsible for cell targeting, first binding to the cell, and then bringing up the F-class subunit (Diederen and Kluytmans, 2006; DuMont and Torres, 2014). $\delta$-hemolysin (hld), composed of a 26-amino acid peptide, can cause membrane damage in a variety of mammalian cells (Otto, 2012). Hld has the ability to lyse erythrocytes and other mammalian cells as well as subcellular structures, such as membrane-bound organelles, spheroids, and protoplasts (Melo et al., 2017).

In the case of the overall hemolysin gene, MRSA appeared slightly more than MSSA. In one study, it was found that the presence of the genes encoding hla and hld significantly affected the antibiotic resistance pattern of MRSA isolates (Motamedi et al., 2018). The prevalence of the hemolysin gene in $S$. aureus is observed in a holistic way, because its diversity is also related to different geographic regions (Mir et al., 2019).

\section{4-3. Superantigen genes (toxic shock syndrome toxin, enterotoxins)}

SAgs are non-glycosylated, low-molecular-weight exoproteins. They are secreted depending on cleavable signal peptides, which are secreted by all human pathogenic $S$. aureus and group A streptococci (Spaulding et al., 2013). SAgs are highly effective $\mathrm{T}$ cell mitogens that can stimulate $\mathrm{T}$ cells. SAg-induced $\mathrm{T}$ cell proliferation is followed by a $\mathrm{T}$ cell unresponsive state, in which activated $\mathrm{T}$ cells fail to proliferate or undergo apoptosis. The SAg system is one of the several ways by which $S$. aureus manipulates the host immune system to prevent the generation of functional adaptive immunity (Tam and Torres, 2019).

TSS is an acute disease that can be potentially fatal. It results in high fever, diffuse erythematous rash, peeling of the skin one to two weeks after onset, and hypotension (Tang et al., 2006; Bonar et al., 2015). This disease attracted considerable attention in 1978 when Todd et al. identified it as a major systemic disease associated with non-invasive $S$. aureus infections in children (Feuillie et al., 2017). TSST is

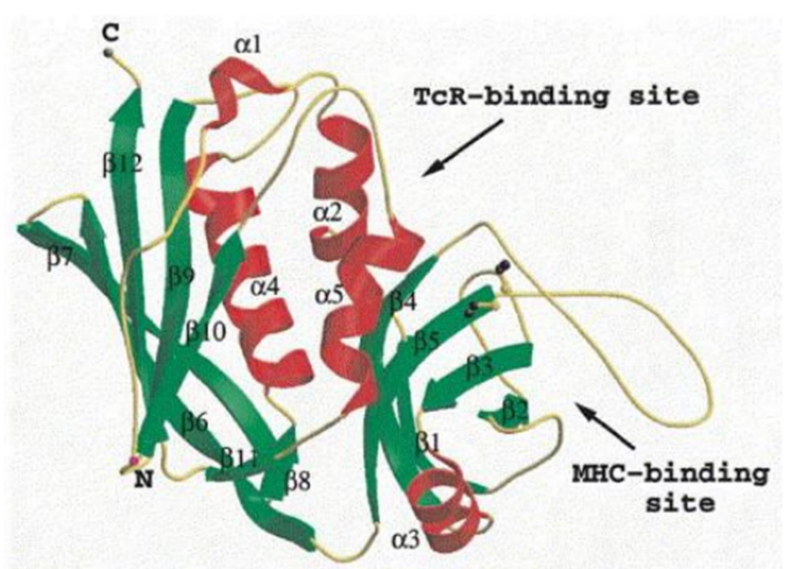

Fig. 3. 3D structure of Staphylococcus enterotoxin B. The polypeptide fold for SEB. Helices are coloured in red, $\beta$-strands in green and loops in yellow. The illustration is adapted from Papageorgiou et al. (Papageorgiou et al., 1998).

a $S$. aureus SAg that triggers TSS by stimulating the release of interleukin (IL)-1, IL-2, tumor necrosis factor- $\alpha$, and other cytokines (Khan et al., 2009).

\section{4-4. Staphylococcal enterotoxins}

Enterotoxins have a common structure consisting of two domain folds, a long central alpha-helix, and specific Nterminal and C-terminal motifs with a beta barrel structure (Fig. 3) (Josse et al., 2017). The exact mechanism of SE is unknown, but it activates the release of cytokines and eventually induces cell death by apoptosis (Soltani et al., 2019). Enterotoxins are the leading cause of food poisoning and can cause severe intestinal peristalsis (Becker et al., 2003). Staphylococcal SAg toxins are a wide range of virulence factors associated with $S$. aureus. In addition to previously known SEs, at present, 29 SEs or enterotoxin-like proteins have been identified (Hu et al., 2021). SEB is a toxin that is highly associated with several outbreaks of food poisoning (Wieneke et al., 1993). SEB is commonly found in humans and mammals, as well as in areas with high levels of environmental pollutants, such as sewage and smoke. SEC from CA-MRSA strains has also been found to cause sepsis, infectious endocarditis, and kidney damage (Diep and Otto, 2008). 


\section{4-5. Other virulence factors (PVL, LukED, ETA, and ETB)}

PVL and LukED are heterologous families in which toxin components are classified as $\mathrm{F}$ or $\mathrm{S}$ proteins. They are separately secreted and assembled on the cell surface to form heterologous oligomeric pores and lyse blood cells (Yanai et al., 2014). Additionally, they are associated with purulent infections and are encoded by two successive and co-transcribed genes that are passed on to bacteriophages, causing leukocyte destruction and tissue necrosis. However, their exact role in skin infections has not yet been identified (Cocchi et al., 2013). PVL was generally found at the beginning of the CA-MRSA epidemic, and the $l u k \mathrm{~S}$ and lukF genes were found in almost all CA-MRSA clones. Recently, PVL has been shown to be associated with CAMRSA in a study on the association between infections that are in progress and strains (Bhatta et al., 2016); however, the association between PVL and CA-MRSA remains controversial. Although PVL can be utilized as a screening marker for CA-MRSA, it is difficult to determine because of the presence of PVL-positive HA-MRSA strains. HAMRSA may lead to the emergence of multidrug-resistant HA-MRSA isolates with increased toxicity (Rossney et al., 2007; Hu et al., 2015). As PVL phages from existing MRSA are expected to spread to other HA-MRSA strains, HAMRSA infections need to be further divided into hospitalborne or community-borne infections (Narita et al., 2001; Klevens et al., 2007).

ETs, also known as specific serine proteases, are secreted virulence factors produced by staphylococci (Shopsin et al., 2003; Abimanyu et al., 2013). These proteases have high substrate specificity and recognize and hydrolyze desmosomal proteins in the skin. ETs are involved in the loss of cell-cell adhesion and cleavage of keratinocyte junctions in the epidermis of the host that can cause skin damage. Strains of ETs include ETA, ETB, ETC, and ETD. ETA and ETB are the most important factors in human skin damage. ETC has not yet been associated with human diseases. These ETs are produced in approximately $5 \%$ of the $S$. aureus strains. ETA is highly prevalent in Europe, Africa, and the United States, whereas ETB is more common in Japan. The production of ETs in certain strains of $S$. aureus is associated with local epidermal infections, such as bullous impetigo and staphylococcal laceration skin syndrome, which are common diseases (Saiman et al., 2003; Healy et al., 2004; Bratu et al., 2005).

\section{CONCLUSION}

We described the resistance of MRSA to $\beta$-lactam antibiotics, with an emphasis on mecA, which is carried by a mobile genetic element called SCCmec. The mecA gene encodes PBP2a that has a low affinity for $\beta$-lactam antibiotics. In this review, the classification criteria for $m e c \mathrm{~A}$, new $m e c$ homologs $(m e c \mathrm{~B}, m e c \mathrm{C}$, and $m e c \mathrm{D})$, and $\mathrm{SCC} m e c$ types (13 SCCmec types that have been found to date) were discussed. SCCmec has entered S. aureus on multiple occasions with a relatively high frequency, but the origin of the mec element remains unclear. MRSA strains possess specific virulence mechanisms controlled by toxins, adhesion proteins, and enzymes. However, the molecular factors underlying the spread of the CA- and HA-MRSA strains remain unknown. Important strains have emerged, such as EMRSA and CA-MRSA, and each strain poses unique challenges to human healthcare and animal husbandry. Therefore, conducting research on the virulence of infectious MRSA strains is important. Further studies are needed to determine the regulation of virulence factors and dynamics of virulence factor transmission in MRSA strains.

\section{ACKNOWLEDGEMENT}

This paper was supported by the Basic Science Research Program through the National Research Foundation of Korea (NRF) funded by the Ministry of Education (NRF2020R1A6A3A01099438), the Center for Women In Science, Engineering and Technology (WISET) and WISET Regional Agency of PKNU Grant funded by the Ministry of Science, and Brain Busan 21 Plus project.

\section{CONFLICT OF ENTEREST}

Authors declare no competing interests. 


\section{REFERENCES}

Abimanyu N, Murugesan S, Krishnan P. High prevalence of exfoliative toxins among carrier isolates of Staphylococcus aureus from healthy individuals from various communities in chennai, south india. Indian J Microbiol. 2013. 53: 288-290.

Aires de Sousa M, de Lencastre H. Bridges from hospitals to the laboratory: Genetic portraits of methicillin-resistant Staphylococcus aureus clones. FEMS Immunol Med Microbiol. 2004. 40: 101-111.

Alvaro-Afonso FJ, Lazaro-Martinez JL, Papanas N. To smoke or not to smoke: Cigarettes have a negative effect on wound healing of diabetic foot ulcers. Int J Low Extrem Wounds. 2018. 17: 258-260.

Anderson AS, Miller AA, Donald RG, Scully IL, Nanra JS, Cooper D, Jansen KU. Development of a multicomponent Staphylococcus aureus vaccine designed to counter multiple bacterial virulence factors. Hum Vaccin Immunother. 2012. 8: 15851594.

Assis LM, Nedeljkovic M, Dessen A. New strategies for targeting and treatment of multi-drug resistant Staphylococcus aureus. Drug Resist Updat. 2017. 31: 1-14.

Aucken HM, Ganner M, Murchan S, Cookson BD, Johnson AP. A new uk strain of epidemic methicillin-resistant Staphylococcus aureus (emrsa-17) resistant to multiple antibiotics. J Antimicrob Chemother. 2002. 50: 171-175.

Baek KT, Grundling A, Mogensen RG, Thogersen L, Petersen A, Paulander W, Frees D. Beta-lactam resistance in methicillinresistant Staphylococcus aureus usa300 is increased by inactivation of the clpxp protease. Antimicrob Agents Chemother. 2014. 58: 4593-4603.

Baig S, Johannesen TB, Overballe-Petersen S, Larsen J, Larsen AR, Stegger M. Novel sccmec type xiii (9a) identified in an st152 methicillin-resistant Staphylococcus aureus. Infect Genet Evol. 2018. 61: 74-76.

Becker K, Friedrich AW, Lubritz G, Weilert M, Peters G, Von Eiff C. Prevalence of genes encoding pyrogenic toxin superantigens and exfoliative toxins among strains of Staphylococcus aureus isolated from blood and nasal specimens. J Clin Microbiol. 2003. 41: 1434-1439.

Benner EJ, Kayser FH. Growing clinical significance of methcillinresistant Staphylococcus aureus. Lancet. 1968. 2: 741-744.

Berube BJ, Bubeck Wardenburg J. Staphylococcus aureus alpha- toxin: Nearly a century of intrigue. Toxins (Basel). 2013. 5: 1140-1166

Bhatta DR, Cavaco LM, Nath G, Kumar K, Gaur A, Gokhale S, Bhatta DR. Association of panton valentine leukocidin (pvl) genes with methicillin resistant Staphylococcus aureus (mrsa) in western nepal: A matter of concern for community infections (a hospital based prospective study). BMC Infect Dis. 2016. 16: 199.

Bonar E, Wojcik I, Wladyka B. Proteomics in studies of Staphylococcus aureus virulence. Acta Biochim Pol. 2015. 62: 367381.

Boulton AJM, Vileikyte L, Ragnarson-Tennvall G, Apelqvist J. The global burden of diabetic foot disease. The Lancet. 2005. 366: 1719-1724.

Bratu S, Eramo A, Kopec R, Coughlin E, Ghitan M, Yost R, Chapnick EK, Landman D, Quale J. Community-associated methicillin-resistant Staphylococcus aureus in hospital nursery and maternity units. Emerg Infect Dis. 2005. 11: 808-813.

Chambers HF, Deleo FR. Waves of resistance: Staphylococcus aureus in the antibiotic era. Nat Rev Microbiol. 2009. 7: 629641.

Chen W, He C, Yang H, Shu W, Cui Z, Tang R, Zhang C, Liu Q. Prevalence and molecular characterization of methicillinresistant Staphylococcus aureus with mupirocin, fusidic acid and/or retapamulin resistance. BMC Microbiol. 2020. 20: 183.

Cikman A, Aydin M, Gulhan B, Karakecili F, Kurtoglu MG, Yuksekkaya S, Parlak M, Gultepe BS, Cicek AC, Bilman FB, Ciftci IH, Kara M, Atmaca S, Ozekinci T. Absence of the mecc gene in methicillin-resistant Staphylococcus aureus isolated from various clinical samples: The first multi-centered study in turkey. J Infect Public Health. 2019. 12: 528-533.

Cocchi P, Taccetti G, Montagnani C, Campana S, Galli L, Braggion C, de Martino M. Evidence of transmission of a pantonvalentine leukocidin-positive community-acquired methicillinresistant Staphylococcus aureus clone: A family affair. Clin Microbiol Infect. 2013. 19: 1158-1162.

Crosby HA, Kwiecinski J, Horswill AR. Staphylococcus aureus aggregation and coagulation mechanisms, and their function in host-pathogen interactions. Adv Appl Microbiol. 2016. 96: $1-41$.

D NE, Perkins S, Francois P, Vaudaux P, Höök M, Foster TJ. Clumping factor $\mathrm{b}$ (clfb), a new surface-located fibrinogenbinding adhesin of Staphylococcus aureus. Mol Microbiol. 1998. 30: 245-257.

da Cruz RMD, Zelli R, Benshain S, da Cruz RMD, Siqueira-Júnior 
JP, Décout JL, Mingeot-Leclercq MP, Mendonça-Junior FJB. Synthesis and evaluation of 2-aminothiophene derivatives as Staphylococcus aureus efflux pump inhibitors. Chem Med Chem. 2020. 15: 716-725.

Dadashi M, Hajikhani B, Darban-Sarokhalil D, van Belkum A, Goudarzi M. Mupirocin resistance in Staphylococcus aureus: A systematic review and meta-analysis. J Glob Antimicrob Resist. 2020. 20: 238-247.

David MZ, Daum RS. Community-associated methicillin-resistant Staphylococcus aureus: Epidemiology and clinical consequences of an emerging epidemic. Clin Microbiol Rev. 2010. 23: 616-687.

Delgado S, Garcia P, Fernandez L, Jimenez E, Rodriguez-Banos M, del Campo R, Rodriguez JM. Characterization of Staphylococcus aureus strains involved in human and bovine mastitis. FEMS Immunol Med Microbiol. 2011. 62: 225-235.

Diederen BM, Kluytmans JA. The emergence of infections with community-associated methicillin resistant Staphylococcus aureus. J Infect. 2006. 52: 157-168.

Diep BA, Otto M. The role of virulence determinants in communityassociated mrsa pathogenesis. Trends Microbiol. 2008. 16: 361-369.

DuMont AL, Torres VJ. Cell targeting by the Staphylococcus aureus pore-forming toxins: It's not just about lipids. Trends in Microbiology. 2014. 22: 21-27.

Fair RJ, Tor Y. Antibiotics and bacterial resistance in the 21st century. Perspect Medicin Chem. 2014. 6: 25-64.

Feuillie C, Formosa-Dague C, Hays LM, Vervaeck O, Derclaye S, Brennan MP, Foster TJ, Geoghegan JA, Dufrene YF. Molecular interactions and inhibition of the staphylococcal biofilmforming protein sdrc. Proc Natl Acad Sci U S A. 2017. 114: 3738-3743.

Fisher JF, Mobashery S. Constructing and deconstructing the bacterial cell wall. Protein Sci. 2020. 29: 629-646.

Fishovitz J, Hermoso JA, Chang M, Mobashery S. Penicillinbinding protein $2 \mathrm{a}$ of methicillin-resistant Staphylococcus aureus. IUBMB Life. 2014. 66: 572-577.

Foster TJ. The mscramm family of cell-wall-anchored surface proteins of gram-positive cocci. Trends Microbiol. 2019. 27: 927-941.

Foster TJ, Geoghegan JA, Ganesh VK, Höök M. Adhesion, invasion and evasion: The many functions of the surface proteins of Staphylococcus aureus. Nat Rev Microbiol. 2014. 12: 49-62.

Fri J, Njom HA, Ateba CN, Ndip RN. Antibiotic resistance and virulence gene characteristics of methicillin-resistant Staphylo- coccus aureus (mrsa) isolated from healthy edible marine fish. Int J Microbiol. 2020. 2020: 9803903.

G CB, Sahukhal GS, Elasri MO. Role of the msaabcr operon in cell wall biosynthesis, autolysis, integrity, and antibiotic resistance in Staphylococcus aureus. Antimicrob Agents Chemother. 2019. 63.

Gomez-Sanz E, Schwendener S, Thomann A, Gobeli Brawand S, Perreten V. First staphylococcal cassette chromosome mec containing a mecb-carrying gene complex independent of transposon tn6045 in a macrococcus canis isolate from a canine infection. Antimicrob Agents Chemother. 2015. 59: 4577-4583.

Gregory ML, Eichenwald EC, Puopolo KM. Seven-year experience with a surveillance program to reduce methicillin-resistant Staphylococcus aureus colonization in a neonatal intensive care unit. Pediatrics. 2009. 123: e790-796.

Harrison EM, Paterson GK, Holden MT, Morgan FJ, Larsen AR, Petersen A, Leroy S, De Vliegher S, Perreten V, Fox LK, Lam TJ, Sampimon OC, Zadoks RN, Peacock SJ, Parkhill J, Holmes MA. A staphylococcus xylosus isolate with a new mecc allotype. Antimicrob Agents Chemother. 2013. 57: 15241528.

Hart J, Christiansen KJ, Lee R, Heath CH, Coombs GW, Robinson JO. Increased emrsa-15 health-care worker colonization demonstrated in retrospective review of emrsa hospital outbreaks. Antimicrobial Resistance and Infection Control. 2014. 3: 7.

Hashemizadeh Z, Hadi N, Mohebi S, Kalantar-Neyestanaki D, Bazargani A. Characterization of sccmec, spa types and multi drug resistant of methicillin-resistant Staphylococcus aureus isolates among inpatients and outpatients in a referral hospital in shiraz, iran. BMC Res Notes. 2019. 12: 614.

Hauck CR, Ohlsen K. Sticky connections: Extracellular matrix protein recognition and integrin-mediated cellular invasion by Staphylococcus aureus. Curr Opin Microbiol. 2006. 9: 511.

Hayden MK, Lolans K, Haffenreffer K, Avery TR, Kleinman K, Li H, Kaganov RE, Lankiewicz J, Moody J, Septimus E, Weinstein RA, Hickok J, Jernigan J, Perlin JB, Platt R, Huang SS. Chlorhexidine and mupirocin susceptibility of methicillinresistant Staphylococcus aureus isolates in the reduce-mrsa trial. J Clin Microbiol. 2016. 54: 2735-2742.

Healy CM, Hulten KG, Palazzi DL, Campbell JR, Baker CJ Emergence of new strains of methicillin-resistant Staphylococcus aureus in a neonatal intensive care unit. Clin Infect Dis. 2004. 39: 1460-1466. 
Herman-Bausier P, Labate C, Towell AM, Derclaye S, Geoghegan JA, Dufrene YF. Staphylococcus aureus clumping factor a is a force-sensitive molecular switch that activates bacterial adhesion. Proc Natl Acad Sci U S A. 2018. 115: 5564-5569.

Herrera A, Kulhankova K, Sonkar VK, Dayal S, Klingelhutz AJ, Salgado-Pabon W, Schlievert PM. Staphylococcal beta-toxin modulates human aortic endothelial cell and platelet function through sphingomyelinase and biofilm ligase activities. mBio. 2017. 8.

Hu DL, Li S, Fang R, Ono HK. Update on molecular diversity and multipathogenicity of staphylococcal superantigen toxins. Animal Diseases. 2021. 1: 7.

Hu Q, Cheng H, Yuan W, Zeng F, Shang W, Tang D, Xue W, Fu J, Zhou R, Zhu J, Yang J, Hu Z, Yuan J, Zhang X, Rao Q, Li S, Chen Z, Hu X, Wu X, Rao X. Panton-valentine leukocidin (pvl)-positive health care-associated methicillin-resistant Staphylococcus aureus isolates are associated with skin and soft tissue infections and colonized mainly by infective pvlencoding bacteriophages. J Clin Microbiol. 2015. 53: 67-72.

Huseby MJ, Kruse AC, Digre J, Kohler PL, Vocke JA, Mann EE, Bayles KW, Bohach GA, Schlievert PM, Ohlendorf DH, Earhart CA. Beta toxin catalyzes formation of nucleoprotein matrix in staphylococcal biofilms. Proc Natl Acad Sci U S A. 2010. 107: 14407-14412.

Jang S. Multidrug efflux pumps in Staphylococcus aureus and their clinical implications. J Microbiol. 2016. 54: 1-8.

Johnson AP, Pearson A, Duckworth G. Surveillance and epidemiology of mrsa bacteraemia in the uk. J Antimicrob Chemother. 2005. 56: 455-462.

Josse J, Laurent F, Diot A. Staphylococcal adhesion and host cell invasion: Fibronectin-binding and other mechanisms. Front Microbiol. 2017. 8: 2433.

Khan AA, Priya S, Saha B. Il-2 regulates seb induced toxic shock syndrome in balb/c mice. PLoS One. 2009. 4: e8473.

Klevens RM, Morrison MA, Nadle J, Petit S, Gershman K, Ray S, Harrison LH, Lynfield R, Dumyati G, Townes JM, Craig AS, Zell ER, Fosheim GE, McDougal LK, Carey RB, Fridkin SK Invasive methicillin-resistant Staphylococcus aureus infections in the united states. Jama. 2007. 298: 1763-1771.

Krakauer T, Stiles BG. The staphylococcal enterotoxin (se) family: Seb and siblings. Virulence. 2013. 4: 759-773.

Ladhani S. Recent developments in staphylococcal scalded skin syndrome. Clin Microbiol Infect. 2001. 7: 301-307.

Lakhundi S, Zhang K. Methicillin-resistant Staphylococcus aureus: Molecular characterization, evolution, and epidemiology. Clin
Microbiol Rev. 2018. 31

Lim WW, Wu P, Bond HS, Wong JY, Ni K, Seto WH, Jit M, Cowling BJ. Determinants of methicillin-resistant Staphylococcus aureus (mrsa) prevalence in the asia-pacific region: A systematic review and meta-analysis. J Glob Antimicrob Resist. 2019. 16: 17-27.

Lindsay JA. Genomic variation and evolution of Staphylococcus aureus. Int J Med Microbiol. 2010. 300: 98-103.

Lindsay JA. Hospital-associated mrsa and antibiotic resistancewhat have we learned from genomics? Int J Med Microbiol. 2013. 303: 318-323.

Linehan D, Etienne J, Sheehan D. Relationship between haemolytic and sphingomyelinase activities in a partially purified betalike toxin from staphylococcus schleiferi. FEMS Immunol Med Microbiol. 2003. 36: 95-102.

Liu L, Shen X, Yu J, Cao X, Zhan Q, Guo Y, Yu F. Subinhibitory concentrations of fusidic acid may reduce the virulence of $S$. aureus by down-regulating sara and saers to reduce biofilm formation and $\alpha$-toxin expression. Front Microbiol. 2020. 11: 25.

Liu X, Deng S, Huang J, Huang Y, Zhang Y, Yan Q, Wang Y, Li Y, Sun C, Jia X. Dissemination of macrolides, fusidic acid and mupirocin resistance among Staphylococcus aureus clinical isolates. Oncotarget. 2017. 8: 58086-58097.

Loncarevic S, Jorgensen HJ, Lovseth A, Mathisen T, Rorvik LM. Diversity of Staphylococcus aureus enterotoxin types within single samples of raw milk and raw milk products. J Appl Microbiol. 2005. 98: 344-350.

Lovseth A, Loncarevic S, Berdal KG. Modified multiplex pcr method for detection of pyrogenic exotoxin genes in staphylococcal isolates. J Clin Microbiol. 2004. 42: 3869-3872.

Luther MK, Parente DM, Caffrey AR, Daffinee KE, Lopes VV, Martin ET, LaPlante KL. Clinical and genetic risk factors for biofilm-forming Staphylococcus aureus. Antimicrob Agents Chemother. 2018. 62.

Melo MCA, Rodrigues CG, Pol-Fachin L. Staphylococcus aureus delta-toxin in aqueous solution: Behavior in monomeric and multimeric states. Biophys Chem. 2017. 227: 21-28.

Mir Z, Nodeh Farahani N, Abbasian S, Alinejad F, Sattarzadeh M, Pouriran R, Dahmardehei M, Mirzaii M, Khoramrooz SS, Darban-Sarokhalil D. The prevalence of exotoxins, adhesion, and biofilm-related genes in Staphylococcus aureus isolates from the main burn center of tehran, iran. Iranian journal of basic medical sciences. 2019. 22: 1267-1274.

Monaco M, Pimentel de Araujo F, Cruciani M, Coccia EM, 
Pantosti A. Worldwide epidemiology and antibiotic resistance of Staphylococcus aureus. Curr Top Microbiol Immunol. 2017. 409: 21-56

Moran GJ, Krishnadasan A, Gorwitz RJ, Fosheim GE, Albrecht V, Limbago B, Talan DA, Group EMINS. Prevalence of methicillin-resistant Staphylococcus aureus as an etiology of community-acquired pneumonia. Clin Infect Dis. 2012. 54: 1126-1133.

Motamedi H, Asghari B, Tahmasebi H, Arabestani MR. Identification of hemolysine genes and their association with antimicrobial resistance pattern among clinical isolates of Staphylococcus aureus in west of iran. Advanced Biomedical Research. 2018. 7: 153-153.

Munoz-Planillo R, Franchi L, Miller LS, Nunez G. A critical role for hemolysins and bacterial lipoproteins in Staphylococcus aureus-induced activation of the nlrp3 inflammasome. J Immunol. 2009. 183: 3942-3948.

Narita S, Kaneko J, Chiba J, Piémont Y, Jarraud S, Etienne J, Kamio Y. Phage conversion of panton-valentine leukocidin in Staphylococcus aureus: Molecular analysis of a pvl-converting phage, phislt. Gene. 2001. 268: 195-206.

Nimmo GR. Usa300 abroad: Global spread of a virulent strain of community-associated methicillin-resistant Staphylococcus aureus. Clin Microbiol Infect. 2012. 18: 725-734.

Oliveira D, Borges A, Simoes M. Staphylococcus aureus toxins and their molecular activity in infectious diseases. Toxins (Basel). 2018. 10.

Otto M. Mrsa virulence and spread. Cell Microbiol. 2012. 14: 15131521.

Otto M. Community-associated mrsa: What makes them special? Int J Med Microbiol. 2013. 303: 324-330.

Peacock SJ, Paterson GK. Mechanisms of methicillin resistance in Staphylococcus aureus. Annu Rev Biochem. 2015. 84: 577601.

Proft T, Fraser JD. Bacterial superantigens. Clin Exp Immunol. 2003. 133: 299-306

Rasheed NA, Hussein NR. Characterization of different virulent factors in methicillin-resistant Staphylococcus aureus isolates recovered from iraqis and syrian refugees in duhok city, iraq. PLoS One. 2020. 15: e0237714.

Rossney AS, Shore AC, Morgan PM, Fitzgibbon MM, O'Connell $\mathrm{B}$, Coleman DC. The emergence and importation of diverse genotypes of methicillin-resistant Staphylococcus aureus (mrsa) harboring the panton-valentine leukocidin gene (pvl) reveal that pvl is a poor marker for community-acquired mrsa strains in ireland. J Clin Microbiol. 2007. 45: 2554-2563.

Saiman L, O'Keefe M, Graham PL, 3rd, Wu F, Saïd-Salim B, Kreiswirth B, LaSala A, Schlievert PM, Della-Latta P. Hospital transmission of community-acquired methicillinresistant Staphylococcus aureus among postpartum women Clin Infect Dis. 2003. 37: 1313-1319.

Samanta D, Elasri MO. The msaabcr operon regulates resistance in vancomycin-intermediate Staphylococcus aureus strains Antimicrob Agents Chemother. 2014. 58: 6685-6695.

Sarkar P, Yarlagadda V, Ghosh C, Haldar J. A review on cell wall synthesis inhibitors with an emphasis on glycopeptide antibiotics. Medchemcomm. 2017. 8: 516-533.

Sassi R, Bond RR, Cairns A, Finlay DD, Guldenring D, Libretti G, Isola L, Vaglio M, Poeta R, Campana M, Cuccia C, Badilini F. Pdf-ecg in clinical practice: A model for long-term preservation of digital 12-lead ecg data. J Electrocardiol. 2017. 50: 776-780

Scherr TD, Hanke ML, Huang O, James DB, Horswill AR, Bayles KW, Fey PD, Torres VJ, Kielian T. Staphylococcus aureus biofilms induce macrophage dysfunction through leukocidin $\mathrm{ab}$ and alpha-toxin. mBio. 2015. 6 .

Schwendener S, Perreten V. The integrase of the macrococcus caseolyticus resistance island mecd (mcrimecd) inserts DNA site-specifically into staphylococcus and bacillus chromosomes. Mol Microbiol. 2018. 110: 455-468.

Seilie ES, Bubeck Wardenburg J. Staphylococcus aureus poreforming toxins: The interface of pathogen and host complexity. Semin Cell Dev Biol. 2017. 72: 101-116.

Senok A, Slickers P, Hotzel H, Boswihi S, Braun SD, Gawlik D, Muller E, Nabi A, Nassar R, Nitschke H, Reissig A, RuppeltLorz A, Mafofo J, Somily AM, Udo E, Ehricht R, Monecke S. Characterisation of a novel sccmec vi element harbouring fusc in an emerging Staphylococcus aureus strain from the arabian gulf region. PLoS One. 2019. 14: e0223985.

Shettigar K, Murali TS. Virulence factors and clonal diversity of Staphylococcus aureus in colonization and wound infection with emphasis on diabetic foot infection. Eur J Clin Microbiol Infect Dis. 2020. 39: 2235-2246.

Shopsin B, Mathema B, Alcabes P, Said-Salim B, Lina G, Matsuka A, Martinez J, Kreiswirth BN. Prevalence of agr specificity groups among Staphylococcus aureus strains colonizing children and their guardians. J Clin Microbiol. 2003. 41: 456459 .

Silva V, Hermenegildo S, Ferreira C, Manaia CM, Capita R, Alonso-Calleja C, Carvalho I, Pereira JE, Maltez L, Capelo 
JL, Igrejas G, Poeta P. Genetic characterization of methicillinresistant Staphylococcus aureus isolates from human bloodstream infections: Detection of $\mathrm{mls}(\mathrm{b})$ resistance. Antibiotics (Basel). 2020. 9.

Singh-Moodley A, Strasheim W, Mogokotleng R, Ismail H, Perovic O. Unconventional sccmec types and low prevalence of the panton-valentine leukocidin exotoxin in south african blood culture Staphylococcus aureus surveillance isolates, 20132016. PLoS One. 2019. 14: e0225726.

Smart H, AlGhareeb AM, Smart SA. 25-hydroxyvitamin d deficiency: Impacting deep-wound infection and poor healing outcomes in patients with diabetes. Adv Skin Wound Care. 2019. 32: 321-328.

Soltani E, Farrokhi E, Zamanzad B, Shahini Shams Abadi M, Deris F, Soltani A, Gholipour A. Prevalence and distribution of adhesins and the expression of fibronectin-binding protein (fnba and fnbb) among Staphylococcus aureus isolates from shahrekord hospitals. BMC Res Notes. 2019. 12: 49.

Spaulding AR, Salgado-Pabón W, Kohler PL, Horswill AR, Leung DYM, Schlievert PM. Staphylococcal and streptococcal superantigen exotoxins. Clinical Microbiology Reviews. 2013. 26: 422-447.

Srisuknimit V, Qiao Y, Schaefer K, Kahne D, Walker S. Peptidoglycan cross-linking preferences of Staphylococcus aureus penicillin-binding proteins have implications for treating mrsa infections. J Am Chem Soc. 2017. 139: 9791-9794.

Tam K, Torres VJ. Staphylococcus aureus secreted toxins and extracellular enzymes. Microbiology Spectrum. 2019. 7: 10.1128/microbiolspec.GPP1123-0039-2018.

Tang J, Wang C, Feng Y, Yang W, Song H, Chen Z, Yu H, Pan X, Zhou X, Wang H, Wu B, Wang H, Zhao H, Lin Y, Yue J, Wu Z, He X, Gao F, Khan AH, Wang J, et al. Streptococcal toxic shock syndrome caused by streptococcus suis serotype 2 . PLoS Med. 2006. 3: e151.

Tong SY, Chen LF, Fowler VG, Jr. Colonization, pathogenicity, host susceptibility, and therapeutics for Staphylococcus aureus: What is the clinical relevance? Semin Immunopathol. 2012. 34: 185-200.

Tong SY, Davis JS, Eichenberger E, Holland TL, Fowler VG, Jr. Staphylococcus aureus infections: Epidemiology, pathophysiology, clinical manifestations, and management. Clin Microbiol Rev. 2015. 28: 603-661.

Typas A, Banzhaf M, Gross CA, Vollmer W. From the regulation of peptidoglycan synthesis to bacterial growth and morphology. Nat Rev Microbiol. 2011. 10: 123-136.
Valsesia G, Rossi M, Bertschy S, Pfyffer GE. Emergence of sccmec type iv and sccmec type v methicillin-resistant Staphylococcus aureus containing the panton-valentine leukocidin genes in a large academic teaching hospital in central switzerland: External invaders or persisting circulators? J Clin Microbiol. 2010. 48: 720-727.

van Duin D, Paterson DL. Multidrug-resistant bacteria in the community: An update. Infect Dis Clin North Am. 2020. 34 709-722.

Vestergaard M, Frees D, Ingmer H. Antibiotic resistance and the mrsa problem. Microbiol Spectr. 2019. 7.

Voskoboinik I, Whisstock JC, Trapani JA. Perforin and granzymes: Function, dysfunction and human pathology. Nat Rev Immunol. 2015. 15: 388-400.

Walsh EJ, Miajlovic H, Gorkun OV, Foster TJ. Identification of the Staphylococcus aureus mscramm clumping factor b (clfb) binding site in the alphac-domain of human fibrinogen. Microbiology (Reading). 2008. 154: 550-558.

Wang S, Li Y, Xiong H, Cao J. A broad-spectrum inhibitory peptide against staphylococcal enterotoxin superantigen sea, seb and sec. Immunol Lett. 2008. 121: 167-172.

Wieneke AA, Roberts D, Gilbert RJ. Staphylococcal food poisoning in the united kingdom, 1969-90. Epidemiol Infect. 1993. 110: 519-531.

Xue T, You Y, Shang F, Sun B. Rot and agr system modulate fibrinogen-binding ability mainly by regulating clfb expression in Staphylococcus aureus nctc8325. Med Microbiol Immunol. 2012. 201: 81-92.

Yanai M, Rocha MA, Matolek AZ, Chintalacharuvu A, Taira Y, Chintalacharuvu K, Beenhouwer DO. Separately or combined, lukg/lukh is functionally unique compared to other staphylococcal bicomponent leukotoxins. PLoS One. 2014. 9: e89308e89308.

Yarwood JM, Bartels DJ, Volper EM, Greenberg EP. Quorum sensing in Staphylococcus aureus biofilms. J Bacteriol. 2004. 186: $1838-1850$.

Yoong P, Torres VJ. The effects of Staphylococcus aureus leukotoxins on the host: Cell lysis and beyond. Curr Opin Microbiol. 2013. 16: 63-69.

Zheng Y, Shang W, Peng H, Rao Y, Zhao X, Hu Z, Yang Y, Hu Q, Tan L, Xiong K, Li S, Zhu J, Hu X, Zhou R, Li M, Rao X. Virulence determinants are required for brain abscess formation through Staphylococcus aureus infection and are potential targets of antivirulence factor therapy. Front Microbiol. 2019. 10: 682 . 
https://doi.org/10.15616/BSL.2021.27.4.195

Cite this article as: Bae J, Jin H, Kim J, Park M, Lee J, Kim S. Molecular Characteristics and Exotoxins of Methicillin-Resistant Staphylococcus aureus. Biomedical Science Letters. 2021. 27: 195-207. 